ORIGINAL ARTICLE

\title{
Effects of physical activity on exercise tests and respiratory function
}

\author{
Y J Cheng, C A Macera, C L Addy, F S Sy, D Wieland, S N Blair
}

Br J Sports Med 2003;37:521-528

\begin{abstract}
Background: Exercise is an important component of pulmonary rehabilitation for patients with chronic lung disease.

Objective: To explore the role of physical activity in maintaining cardiac and respiratory function in healthy people.

Methods: Cardiorespiratory fitness was measured by a maximal treadmill test (MTT), and respiratory function was tested by spirometry. The cross sectional study included data from 24536 healthy persons who were examined at the Cooper Clinic between 1971 and 1995; the longitudinal study included data from 5707 healthy persons who had an initial visit between 1971 and 1995 and a subsequent visit during the next five years. All participants were aged $25-55$ years and completed a cardiorespiratory test and a medical questionnaire.

Results: In the cross sectional study, after controlling for covariates, being active and not being a recent smoker were associated with better cardiorespiratory fitness and respiratory function in both men and women. In the follow up study, persons who remained or became active had better MTT than persons who remained or became sedentary. Men who remained active had higher forced expiratory volume in one second $\left(F E V_{1}\right)$ and forced vital capacity $(F V C)$ than the other groups. Smoking was related to lower cardiorespiratory fitness and respiratory function.

Conclusions: Physical activity and non-smoking or smoking cessation is associated with maintenance of cardiorespiratory fitness. Change in physical activity habits is associated with change in cardiorespiratory fitness, but respiratory function contributed little to this association during a five year follow up.
\end{abstract}

See end of article for authors' affiliations a mpaired cardiovascular and respiratory functions are associated with increased mortality and morbidity. ${ }^{2}$ Physical activity is known to improve physical fitness and to reduce morbidity and mortality from numerous chronic conditions. ${ }^{3}$ Treadmill tests and spirometric tests are important measurements for evaluating cardiovascular and respiratory functions. The positive relation between physical activity and a treadmill test is much more consistent than that between physical activity and spirometric parameters. $^{45}$ There are few longitudinal studies on physical activity and respiratory function in the general population. ${ }^{5}$ Most studies on the effects of physical activity on respiratory function are cross sectional ones on special populations such as athletes or patients with chronic obstructive pulmonary disease. ${ }^{6-9}$ Physical activity rehabilitation is widely used in patients with cardiovascular and respiratory diseases. Exploration of the relation between physical activity and cardiovascular and respiratory functions will aid in understanding the mechanisms of how physical activity improves patients' quality of life and in finding a better way to evaluate effects of rehabilitation. The major purpose of this combined cross sectional and longitudinal study is to explore the role of respiratory function on the association of change in physical activity habits and change in cardiorespiratory fitness in healthy people.

\section{METHODS}

\section{Study population}

Study participants were examined at the Cooper Clinic in Dallas, Texas. Most (98\%) were white, and $80 \%$ were college graduates. Most participants work in executive or professional positions. There were 29819 persons who had a cardiorespiratory function examination between 1971 and
1995, and 9580 had at least two evaluations of cardiorespiratory function during this period.

There is a period from late childhood through adolescence in which maturation significantly increases forced vital capacity (FVC) and forced expiratory volume in the first second $\left(\mathrm{FEV}_{1}\right)$ independent of growth. ${ }^{10} \mathrm{~A}$ cross sectional study of people aged 55 years or above found that self reported leisure time physical activity correlated poorly with peak oxygen consumption and exercise duration as measured by a maximal treadmill test (MTT), probably because of age related differences in choices of physical activity. ${ }^{11}$ In the light of these observations, only adults aged $25-55$ years were included in the present study. We also excluded people who had any self reported physician diagnosed chronic disease (arthritis, stroke, diabetes, hypertension, cancer, heart attack, chronic cough, or bronchitis), injury, abnormal exercise electrocardiogram, MTT less than six minutes, or $\mathrm{FEV}_{1} /$ FVC $\%<60 \%$ at the first or second visit.

A total of 24536 persons ( 19150 men and 5386 women) who met our criteria were evaluated in the cross sectional study. The longitudinal study consisted of 5707 persons (4952 men and 755 women) who had a second visit between six months and five years after the first visit. The mean (SD) interval between these two visits was 18.7 (10.8) months.

\section{Measurements}

Each visit consisted of a thorough clinical examination by a doctor, various clinical assessments, and self reports of

Abbreviations: $\mathrm{BMI}$, body mass index; $\mathrm{FEV}_{1}$, forced expiratory volume in the first second; FVC, forced vital capacity; MTT, maximal treadmill test 
personal and family health histories and health habits. Before the examination, all participants fasted for at least 12 hours and signed a written informed consent. The study was reviewed and approved annually by The Cooper Institute Institutional Review Board.

Cardiorespiratory fitness was determined by MTT with the Balke protocol. ${ }^{12}$ Respiratory function was measured by spirometry.

We used four parameters to assess cardiorespiratory functions: MTT, $\mathrm{FEV}_{1}, \mathrm{FVC}$, and $\mathrm{FEV}_{1} / \mathrm{FVC} \%$. Respiratory function measurements, $\mathrm{FEV}_{1}$ and FVC, were obtained with a Collins $42 \mathrm{l}$ Survey spirometer. Each person repeated the complete test at least three times. If the two highest FVCs agreed within 10\%, no additional trials were applied. A clinic doctor reviewed all results.

Information in the medical history questionnaire served as a reference for the doctor in evaluating and examining the participant. The same questionnaire was used at every visit. Patients were given general health counselling by a doctor after each assessment.

Physical activity was assessed at each visit through self reported regular exercise patterns for the three months before the examination. For the cross sectional study, we calculated a five level physical activity index. Those who reported no regular exercise were classified as sedentary. Among those who reported any regular exercise, four levels of activity were defined. The first three levels were determined by miles walked or jogged per week: high $(>20)$, moderate $(10.1-20)$, low $(\leqslant 10)$. The fourth level, called "other," included those who participated in regular physical activity but not walking or jogging.

For the longitudinal study, those involved in any kind of regular exercise were classified as active (A), the others were classified as sedentary (S). There were four combinations of physical activity status for the first two visits: A/A, active at both the first and second visits; A/S, active at the first and sedentary at the second; S/A, sedentary at the first visit and active at the second; and S/S, sedentary at both visits.

Current smoking and alcohol drinking status each had two categories: yes or no. For the longitudinal study, first and second visit information on smoking and alcohol drinking were divided into four levels: used at both visits (persistent users), used at the first visit and not used at the second visit (quitters), not used at the first visit and used at the second visit (initiators), and not used at either visit (never used).

Additional variables for this report included sex, age at the first visit, height and weight, body mass index (BMI), and length of follow up. Height and weight were measured on a standard doctor's scale and stadiometer. BMI was calculated as weight $(\mathrm{kg}) /$ height $\left(\mathrm{m}^{2}\right)$.

\section{Statistical methods}

All analyses were separate for women and men and used the SAS statistical software package (SAS Institute, Cary, North Carolina, USA). Generalised least squares regression was used to identify the set of factors associated with the four measures of cardiorespiratory function $\left(\mathrm{MTT}_{1} \mathrm{FEV}_{1}, \mathrm{FVC}\right.$, and $\mathrm{FEV}_{1} / \mathrm{FVC} \%$ ). A $95 \%$ confidence interval (CI) was calculated for each least squares mean.

In the longitudinal study, the differences in cardiorespiratory function between the first and second visit were compared among or across the four physical activity groups. Because cardiorespiratory function at the first visit was associated with differences between the first and second examination, we stratified the participants by baseline quintile cut points (table 1) to inspect the data visually, and also included baseline values in multivariable models to control for baseline variation.
Table 1 Quintiles of cardiorespiratory function for men and women (the Aerobics Center Longitudinal Study, 1971-1995)

\begin{tabular}{|c|c|c|c|c|}
\hline Quintile & MTT (min) & $\mathrm{FEV}_{1}$ (litres) & FVC (litres) & $\mathrm{FEV}_{1} / \mathrm{FVC}(\%)$ \\
\hline \multicolumn{5}{|l|}{ Men } \\
\hline Q1 & $<14.5$ & $<3.4$ & $<4.4$ & $<73.0$ \\
\hline Q2 & $14.5-16.9$ & $3.4-3.7$ & $4.4-4.7$ & $73.0-76.9$ \\
\hline Q3 & $17.0-19.4$ & $3.8-4.0$ & $4.8-5.1$ & 77.0-79.9 \\
\hline Q4 & $19.5-22.1$ & $4.1-4.4$ & $5.2-5.5$ & $80.0-83.9$ \\
\hline Q5 & $>22.1$ & $>4.4$ & $>5.5$ & $>83.9$ \\
\hline \multicolumn{5}{|l|}{ Women } \\
\hline Q1 & $<10.0$ & $<2.4$ & $<3.1$ & $<75.0$ \\
\hline Q2 & $10.0-12.1$ & $2.4-2.6$ & $3.1-3.3$ & $75.0-78.9$ \\
\hline Q3 & $12.2-14.6$ & $2.7-2.8$ & $3.4-3.5$ & $79.0-81.9$ \\
\hline Q4 & $14.7-16.9$ & $2.9-3.1$ & $3.6-3.8$ & $82.0-84.9$ \\
\hline Q5 & $>16.9$ & $>3.1$ & $>3.8$ & $>84.9$ \\
\hline
\end{tabular}

All multivariable models included change in physical activity, age at first visit, change in smoking and alcohol consumption, and length of follow up in the longitudinal study. In addition, BMI was included in the model to control for the association of this factor with MTT, and height was included in models for $\mathrm{FEV}_{1}, \mathrm{FVC}$, and $\mathrm{FEV}_{1} / \mathrm{FVC} \%$ to control for its association with these spirometry measures. Age, height, and BMI were entered as continuous variables. After excluding the people who did not walk or jog, we examined the relation of miles of walking/jogging and cardiorespiratory function. Statistical significance for all tests was set at $p \leqslant 0.05$. We used the Bonferroni method to control for multiple comparisons.

\section{RESULTS}

\section{Cross sectional study}

MTT correlated with $\mathrm{FEV}_{1}(r=0.47, \mathrm{p}<0.001)$, FVC $(r=$ $0.50, \mathrm{p}<0.001)$, and miles of walking or jogging $(r=0.49$, $\mathrm{p}<0.001)$. FEV 1 was highly associated with FVC $(r=0.89$, $\mathrm{p}<0.001)$. The correlation coefficients for miles of walking and jogging and respiratory functions $\left(\mathrm{FEV}_{1}, \mathrm{FVC}\right.$, and $\mathrm{FEV}_{1} /$ FVC\% $)$ were $0.10(\mathrm{p}<0.001), 0.01(\mathrm{p}<0.001)$, and $0.01(\mathrm{p}=$ 0.067 ) respectively.

Table 2 shows the characteristics of the 24536 healthy persons aged 25-55 years by sex in the cross sectional study. For both men and women, the mean age was about 41 years, and $64 \%$ were sedentary. About $21 \%$ of men and $14 \%$ of women were current smokers. About $26 \%$ of men and $37 \%$ of women did not drink alcohol.

Univariate analyses showed that being sedentary, smoking, and not consuming alcohol were related to lower MTT, FEV and FVC in both men and women. Smoking was also associated with a lower level of the $\mathrm{FEV}_{1} / \mathrm{FVC}$ ratio. In the multivariate analyses, controlling for the other variables in table 3, respiratory function levels did not differ significantly between current drinkers and non-drinkers. However, sedentary status and smoking retained their significant associations with respiratory function (table 3 ).

\section{Longitudinal study}

The mean changes in cardiorespiratory function were examined by physical activity change category, controlling for smoking and drinking changes, age, baseline BMI (for MTT), and baseline height (for respiratory function). For men, an increase in physical activity improved MTT more than respiratory function parameters. Table 4 shows the mean changes and $\mathrm{p}$ values between physical activity groups.

Mean values of MTT were higher at baseline for both A/A and S/A groups than either A/S or S/S groups among men 
Table 2 Cross sectional study: selected characteristics of participants (the Aerobics Center Longitudinal Study, 1971-1995)

\begin{tabular}{lll}
\hline Characteristic & Men $(\mathbf{n}=19150)$ & Women $(\mathbf{n}=5386)$ \\
\hline MTT (min) & $17.80(4.96)$ & $12.88(4.57$ \\
FEV $_{1}$ (litres) & $3.89(0.67)$ & $2.80(0.50)$ \\
FVC (litres) FEV $_{1} / \mathrm{FVC} \%(\%)$ & $7.99(0.79)$ & $3.51(0.56)$ \\
Age (years) & $40.86(7.61)$ & $79.82(8.15)$ \\
Height (cm) & $178.95(6.37)$ & $40.47(7.77)$ \\
Weight (kg) & $83.89(13.22)$ & $164.41(5.98)$ \\
BMl & $26.16(3.69)$ & $22.50(4.02)$ \\
Physical activity & & \\
High & $987(5.15 \%)$ & $193(3.58 \%)$ \\
Moderate & $1897(9.91 \%)$ & $482(8.95 \%)$ \\
Low & $3868(20.20 \%)$ & $1,158(21.50 \%)$ \\
Other & $209(1.09 \%)$ & $100(1.86 \%)$ \\
Sedentary & $12189(63.65 \%)$ & $3453(64.11 \%)$ \\
Current smoking & & \\
Yes & $3988(20.83 \%)$ & $745(13.83 \%)$ \\
$\quad$ No & $15162(79.17 \%)$ & $4641(86.17 \%)$ \\
Current drinking & & \\
Yes & $14103(73.64 \%)$ & $3414(63.39 \%)$ \\
No & $5047(26.36 \%)$ & $1972(36.61 \%)$ \\
\hline
\end{tabular}

Values are mean (SD) or number (\%). Levels of physical activity were high ( $>20$ miles a week), moderate (10-20 miles a week), low ( $<20$ miles a week), other than running, and none (sedentary).

$M T T$, Maximal treadmill test; $F_{E V}$, forced expiratory volume in the first second; FVC, forced vital capacity; BMI, body mass index.

(20.60, 19.02, 17.07, 16.13 minutes) and women (15.45, $14.88,12.50,11.48$ minutes), even after controlling for changes in smoking and drinking habits and BMI. Because of the baseline differences in MTT, we divided the subjects into five groups based on baseline cardiorespiratory function quintile values.

Figure 1 illustrates that, within each quintile, if men remained active or became active, they improved MTT $(p<0.001)$. For example, the mean changes in MTT for A/A, $\mathrm{A} / \mathrm{S}, \mathrm{S} / \mathrm{A}$, and $\mathrm{S} / \mathrm{S}$ men in the lowest quintile were $2.89,2.40$, 3.50 , and 1.52 respectively, controlling for other variables. Participants in the lowest quintile had more improvement in cardiorespiratory fitness if they changed from a sedentary to an active lifestyle than did participants in the higher baseline fitness groups.

Mean changes in $\mathrm{FEV}_{1}$ in the A/A group were higher than the mean changes in each of the other physical activity groups in each quintile (fig 2). The mean change between the A/A group and each of the other groups $(\mathrm{A} / \mathrm{S}, \mathrm{S} / \mathrm{A}$, and $S / S)$ was significant $(p=0.012, p<0.001, p<0.001$ respectively).

Figures 3 and 4 indicate that in the lower two quintiles of $\mathrm{FVC}$ and $\mathrm{FEV}_{1} / \mathrm{FVC} \%$, the $\mathrm{A} / \mathrm{A}$ men tended to improve more than the other men.

In women, there were no significant differences in $\mathrm{FEV}_{1}$, $\mathrm{FVC}$, and $\mathrm{FEV}_{1} / \mathrm{FVC} \%$ within activity groups and only a few differences in MTT (table 4), so we did not include figures for the women's results.

After controlling for other variables, adults who never smoked had a greater mean change in MTT ( 1.50 minutes) than quitters (0.97 minute) and persistent smokers (0.81 minute), with Bonferroni adjusted $\mathrm{p}$ values of 0.010 and 0.002 respectively. Men who never smoked had a greater mean change in $\mathrm{FEV}_{1}$ (0.01 litre) and FVC (0.02 litre) than men who smoked at both examinations $(-0.06$ to -0.03$)$ (adjusted $\mathrm{p}=0.001$ and 0.025 respectively). Women who

Table 3 Cross sectional study (the Aerobics Center Longitudinal Study, 1971-1995)

\begin{tabular}{|c|c|c|c|c|}
\hline Variable & $M T T$ (min) & FEV $_{1}$ (litres) & FVC (litres) & $\mathrm{FEV}_{1} / \mathrm{FVC}(\%)$ \\
\hline \multicolumn{5}{|l|}{ Men } \\
\hline \multicolumn{5}{|l|}{ Physical activity } \\
\hline High & 23.31 (23.08 to 23.54$)$ & 4.02 (3.98 to 4.06$)$ & 5.14 (5.10 to 5.19$)$ & 78.30 (77.81 to 78.79$)$ \\
\hline Moderate & $21.00(20.83$ to 21.16$)$ & 3.93 (3.90 to 3.96$)$ & 5.07 (5.04 to 5.10$)$ & 77.71 (77.34 to 78.08$)$ \\
\hline Low & $18.32(18.20$ to 18.45$)$ & 3.89 (3.87 to 3.91$)$ & 4.98 (4.96 to 5.01$)$ & $78.17(77.90$ to 78.44$)$ \\
\hline Other & $18.84(18.37$ to 19.31$)$ & 3.94 (3.86 to 4.02$)$ & $5.06(4.98$ to 5.15$)$ & 78.98 (77.95 to 79.01$)$ \\
\hline Sedentary & 15.69 (15.62 to 15.77$)$ & $3.79(3.78$ to 3.81$)$ & $4.87(4.86$ to 4.89$)$ & $77.97(77.80$ to 78.13$)$ \\
\hline \multicolumn{5}{|l|}{ Current smoking } \\
\hline Yes & $18.49(18.34$ to 18.65$)$ & 3.83 (3.80 to 3.85$)$ & 4.94 (4.91 to 4.97$)$ & 77.57 (77.23 to 77.92$)$ \\
\hline No & $20.37(20.25$ to 20.54$)$ & 4.00 (3.98 to 4.02$)$ & $5.11(5.09$ to 5.13$)$ & 78.47 (78.22 to 78.73$)$ \\
\hline \multicolumn{5}{|l|}{ Current drinking } \\
\hline Yes & $19.58(19.47$ to 19.71$)$ & 3.92 (3.90 to 3.94$)$ & 5.04 (5.01 to 5.06$)$ & 78.00 (77.73 to 78.25$)$ \\
\hline No & 19.28 (19.12 to 19.43$)$ & 3.91 (3.88 to 3.93$)$ & 5.01 (4.99 to 5.04$)$ & 78.06 (77.72 to 78.39$)$ \\
\hline \multicolumn{5}{|l|}{ Difference } \\
\hline 5 years older & $-0.74(-0.78$ to -0.71$)$ & $-0.26(-0.27$ to -0.25$)$ & $-0.27(-0.28$ to -0.26$)$ & $-0.53(-0.60$ to -0.46$)$ \\
\hline 5 unit BMI higher & $-2.52(-2.59$ to -2.47$)$ & - & - & - \\
\hline $5 \mathrm{~cm}$ taller & - & $0.41(0.40$ to 0.42$)$ & $0.61(0.60$ to 0.63$)$ & $-0.71(-0.79$ to -0.62$)$ \\
\hline \multicolumn{5}{|l|}{ Women } \\
\hline \multicolumn{5}{|l|}{ Physical activity } \\
\hline High & $18.69(18.20$ to 19.20$)$ & 2.86 (2.80 to 2.92$)$ & 3.61 (3.54 to 3.67 ) & 79.36 (79.20 to 80.52$)$ \\
\hline Moderate & $15.86(15.54$ to 16.19$)$ & $2.82(2.78$ to 2.86$)$ & 3.58 (3.54 to 3.62$)$ & 78.78 (78.01 to 79.55$)$ \\
\hline Low & $13.44(13.21$ to 13.67$)$ & $2.78(2.75$ to 2.81$)$ & 3.51 (3.48 to 3.54$)$ & 79.22 (78.77 to 79.76$)$ \\
\hline Other & 13.95 (13.27 to 14.63$)$ & 2.81 (2.73 to 2.90 ) & 3.57 (3.48 to 3.66$)$ & 78.86 (77.27 to 80.44$)$ \\
\hline Sedentary & 10.95 (10.80 to 11.10$)$ & 2.71 (2.68 to 2.73$)$ & $3.43(3.41$ to 3.45$)$ & 79.08 (78.73 to 79.42$)$ \\
\hline \multicolumn{5}{|l|}{ Current smoking } \\
\hline Yes & $13.86(13.55$ to 14.16$)$ & 2.73 (2.69 to 2.76$)$ & 3.50 (3.45 to 3.53$)$ & 78.07 (77.36 to 78.79$)$ \\
\hline No & 15.30 (15.12 to 15.49$)$ & $2.87(2.84$ to 2.89$)$ & $3.59(3.56$ to 3.61$)$ & 80.05 (79.61 to 80.48$)$ \\
\hline \multicolumn{5}{|l|}{ Current drinking } \\
\hline Yes & $14.97(14.75$ to 15.12$)$ & 2.81 (2.79 to 2.84 ) & 3.56 (3.53 to 3.59 ) & 78.99 (78.62 to 79.64$)$ \\
\hline No & 14.19 (13.94 to 14.44$)$ & $2.78(2.75$ to 2.81$)$ & 3.52 (3.49 to 3.55 ) & 79.13 (78.40 to 79.57$)$ \\
\hline \multicolumn{5}{|l|}{ Difference } \\
\hline 5 years older & $-0.76(-0.82$ to -0.70$)$ & $-0.22(-0.23$ to -0.20$)$ & $-0.19(-0.21$ to -0.17$)$ & $-0.96(-1.10$ to -0.82$)$ \\
\hline 5 unit BMI higher & $-1.72(-1.84$ to -1.61$)$ & - & - & - \\
\hline $5 \mathrm{~cm}$ taller & - & $0.30(0.28$ to 0.32$)$ & $0.44(0.42$ to 0.46$)$ & $-0.64(-0.82$ to -0.46$)$ \\
\hline
\end{tabular}


Table 4 Longitudinal study: mean change in cardiorespiratory function differences by physical activity change categories (the Aerobics Center Longitudinal Study, 1971-1995)

\begin{tabular}{|c|c|c|c|c|c|c|c|c|c|}
\hline \multicolumn{10}{|c|}{ (A) Least square means } \\
\hline \multirow[b]{2}{*}{$\begin{array}{l}\text { Activity } \\
\text { habit } \\
\text { change }\end{array}$} & & \multicolumn{4}{|l|}{ Men } & \multicolumn{4}{|l|}{ Women } \\
\hline & & $M T \pi(\min )$ & $\begin{array}{l}\text { FEV }_{1} \\
\text { (litres) }\end{array}$ & $\begin{array}{l}\text { FVC } \\
\text { (litres) }\end{array}$ & $\mathrm{FEV}_{1} / \mathrm{FVC}(\%)$ & $\begin{array}{l}\text { MTT } \\
\text { (min) }\end{array}$ & $\begin{array}{l}\mathrm{FEV}_{1} \\
\text { (litres) }\end{array}$ & $\begin{array}{l}\text { FVC } \\
\text { (litres) }\end{array}$ & $\mathrm{FEV}_{1} / \mathrm{FVC}(\%)$ \\
\hline $\begin{array}{l}\text { A/A } \\
A / S \\
S / A \\
S / S\end{array}$ & & $\begin{array}{l}1.51 \\
0.74 \\
1.82 \\
0.25\end{array}$ & $\begin{array}{l}0.05 \\
-0.03 \\
-0.03 \\
-0.04\end{array}$ & $\begin{array}{l}0.07 \\
0.02 \\
0.02 \\
0.01\end{array}$ & $\begin{array}{l}-0.25 \\
-0.50 \\
-0.21 \\
-0.12\end{array}$ & $\begin{array}{l}1.02 \\
0.31 \\
1.28 \\
0.10\end{array}$ & $\begin{array}{l}0.04 \\
0.01 \\
-0.04 \\
-0.03\end{array}$ & $\begin{array}{l}0.04 \\
0.00 \\
-0.01 \\
-0.02\end{array}$ & $\begin{array}{l}0.01 \\
0.45 \\
-0.83 \\
-0.34\end{array}$ \\
\hline \multicolumn{10}{|c|}{ (B) Multiple Comparisons } \\
\hline \multirow[b]{2}{*}{ Group A } & \multirow[b]{2}{*}{ Group B } & \multicolumn{4}{|c|}{ Bonferroni adjusted $\mathrm{p}$ values for men } & \multicolumn{4}{|c|}{ Bonferroni adjusted $p$ values for women } \\
\hline & & $M \pi(\min )$ & FEV $_{1}$ (litres) & FVC (litres) & $\mathrm{FEV}_{1} / \mathrm{FVC}(\%)$ & $M \pi T$ (min) & FEV $_{1}$ (litres) & FVC (litres) & $\mathrm{FEV}_{1} / \mathrm{FVC}(\%)$ \\
\hline $\begin{array}{l}A / A \\
A / A \\
A / A \\
A / S \\
A / S \\
S / A\end{array}$ & $\begin{array}{l}\text { A/S } \\
\text { S/A } \\
\text { S/S } \\
\text { S/A } \\
\text { S/S } \\
S / S\end{array}$ & $\begin{array}{l}0.001 \\
0.007 \\
0.001 \\
0.001 \\
0.001 \\
0.001\end{array}$ & $\begin{array}{l}0.011 \\
0.001 \\
0.001 \\
\mathrm{~ns} \\
\mathrm{~ns} \\
\mathrm{~ns}\end{array}$ & $\begin{array}{l}0.027 \\
0.001 \\
0.001 \\
\mathrm{~ns} \\
\mathrm{~ns} \\
\mathrm{~ns}\end{array}$ & $\begin{array}{l}\text { ns } \\
\text { ns } \\
\text { ns } \\
\text { ns } \\
\text { ns } \\
\text { ns }\end{array}$ & $\begin{array}{l}\text { ns } \\
\text { ns } \\
0.001 \\
0.007 \\
\text { ns } \\
0.001\end{array}$ & $\begin{array}{l}\text { ns } \\
\text { ns } \\
\text { ns } \\
\text { ns } \\
\text { ns } \\
\text { ns }\end{array}$ & $\begin{array}{l}\text { ns } \\
\text { ns } \\
\text { ns } \\
\text { ns } \\
\text { ns } \\
\text { ns }\end{array}$ & $\begin{array}{l}\text { ns } \\
\text { ns } \\
\text { ns } \\
\text { ns } \\
\text { ns } \\
\text { ns }\end{array}$ \\
\hline \multicolumn{10}{|c|}{$\begin{array}{l}\text { Controlled for smoking and drinking habit change; age, baseline BMI (for MTT), baseline height (for } \mathrm{FEV}_{1}, \mathrm{FVC} \text {, and FEV } 1 / \mathrm{FVC} \% \text { ), cardiorespiratory value at } \\
\text { baseline; and follow up time. } \\
\text { MTT, maximal treadmill test; FEV } \\
\text { visit; } \mathrm{A} / \mathrm{S} \text {, active at the first and sedentary at the second; S/A, sedentary at the first visit and active at the second; and S/S, sedentary at both visits; ns, not } \\
\text { significant. }\end{array}$} \\
\hline
\end{tabular}

never smoked had a significantly greater MTT difference (1.49 minutes) than persistent smokers (0.58 minute) (adjusted $\mathrm{p}=0.010$ ). No other significant differences were found for changes in smoking habit on cardiorespiratory parameters. We found no evidence that changes in alcohol intake were associated with changes in cardiorespiratory function.

\section{DISCUSSION}

Physical inactivity and low cardiorespiratory fitness are recognised as important causes of morbidity and mortality..$^{2-4} 13$ The cross sectional and longitudinal data presented in this report show the relation between physical activity and cardiorespiratory function for healthy men and women aged 25-55 years.

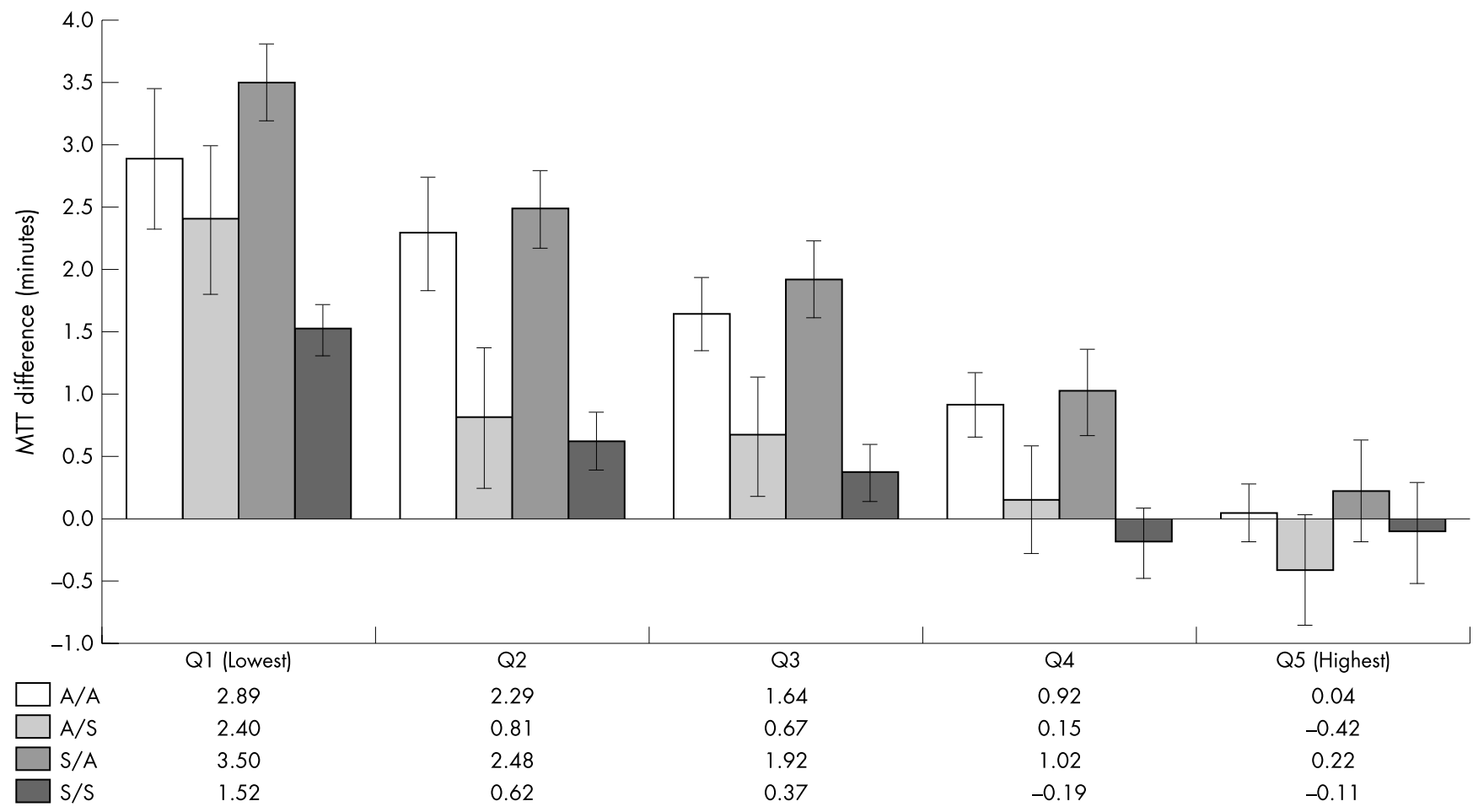

Baseline MTT quintile

Figure 1 Longitudinal study for men: differences in maximal treadmill time (MTT) and physical activity change categories by quintile of baseline MTT (the Aerobics Center Longitudinal Study, 1971-1995). 


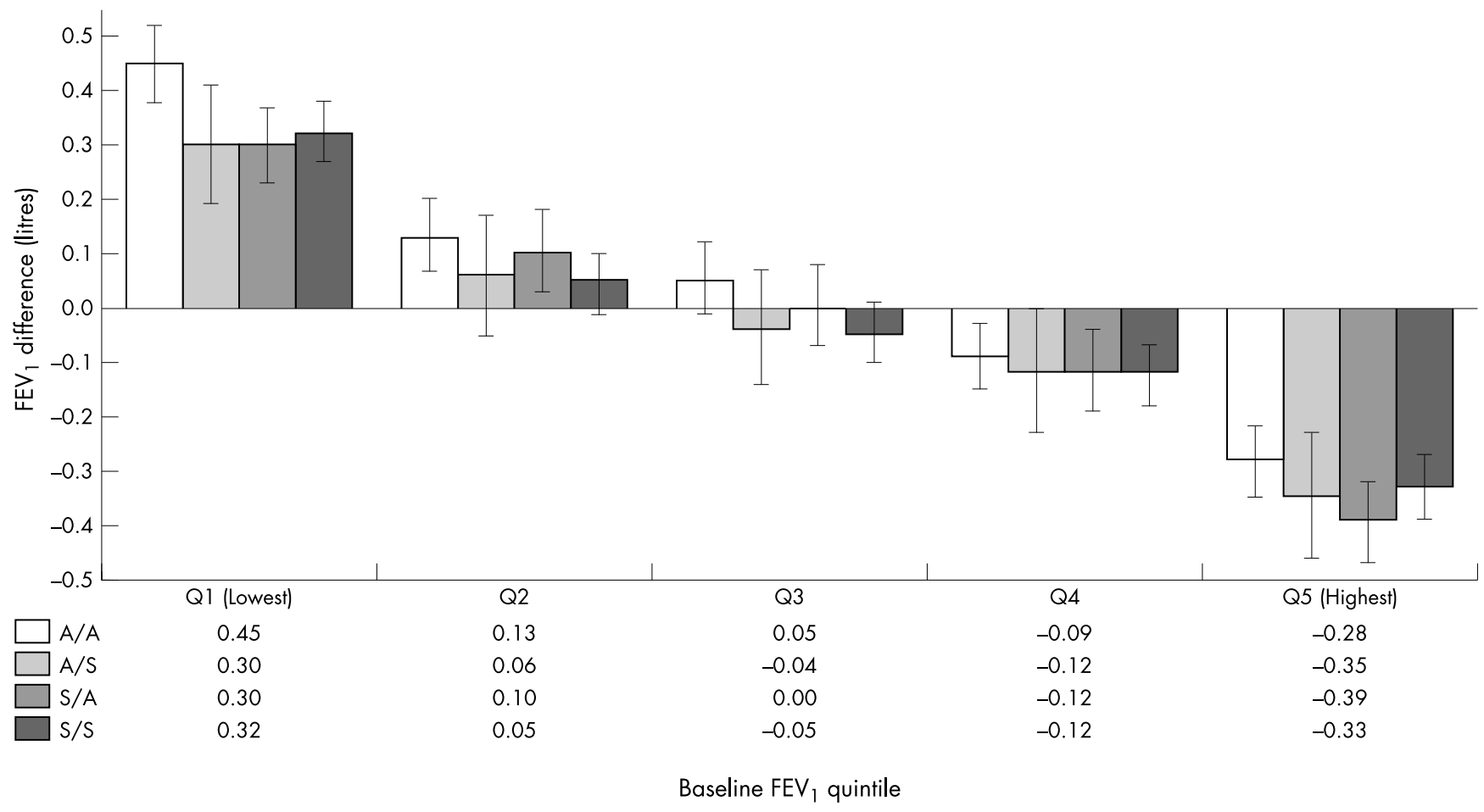

Figure 2 Longitudinal study for men: differences in forced expiratory volume in the first second $\left(\mathrm{FEV}_{1}\right)$ and physical activity change categories by quintile of baseline $\mathrm{FEV}_{1}$ (the Aerobics Center Longitudinal Study, 1971-1995).

It is generally accepted that people with higher levels of physical activity tend to have higher levels of fitness and that physical activity can improve cardiorespiratory fitness. ${ }^{3}$ In both our cross sectional and longitudinal study, higher levels of physical activity were strongly associated with longer MTTs, a finding consistent with other studies. ${ }^{4}{ }^{14}$

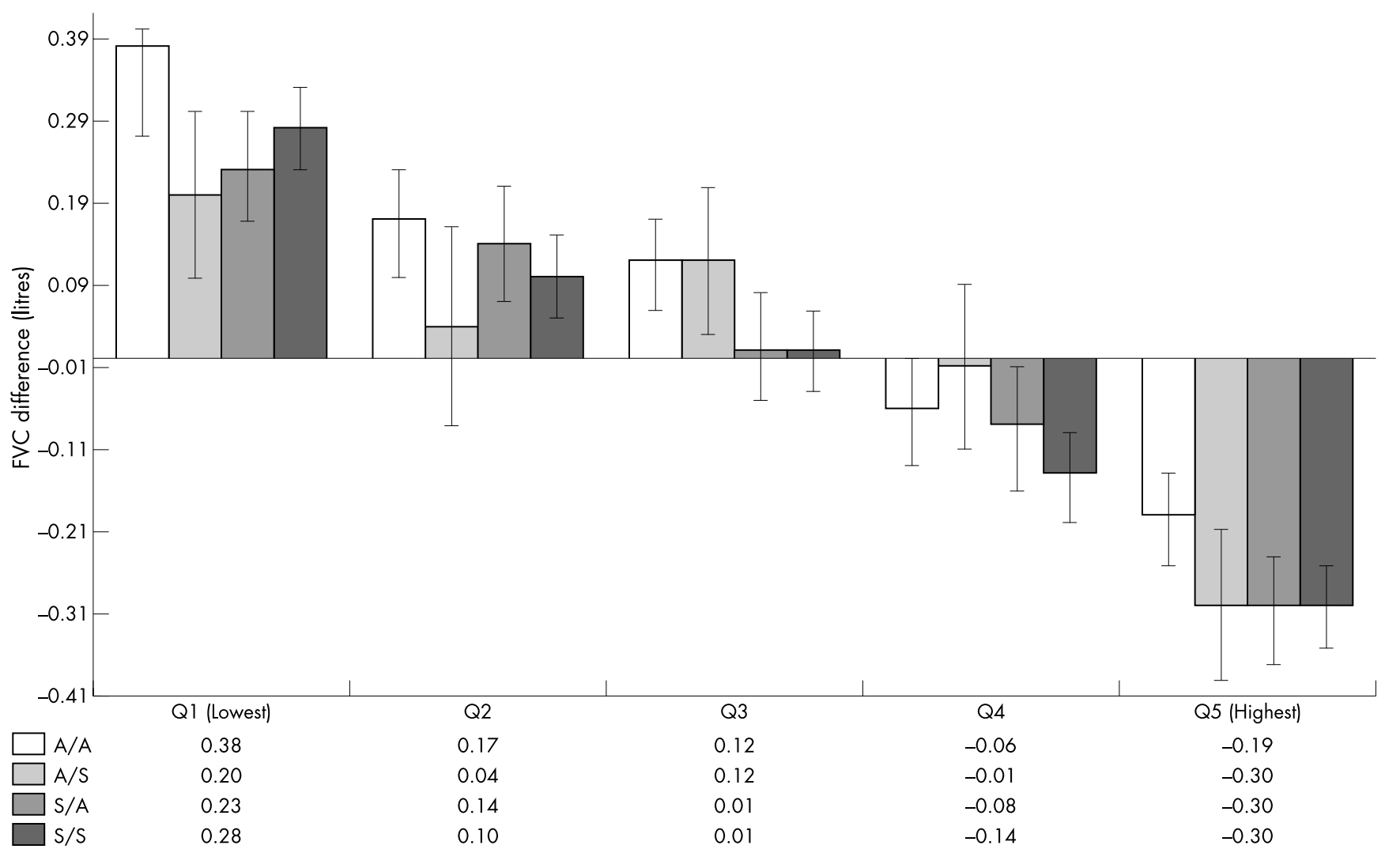

Baseline FVC quintile

Figure 3 Longitudinal study for men: differences in forced vital capacity (FVC) and physical activity change categories by quintile of baseline FVC (the Aerobics Center Longitudinal Study, 1971-1995). 


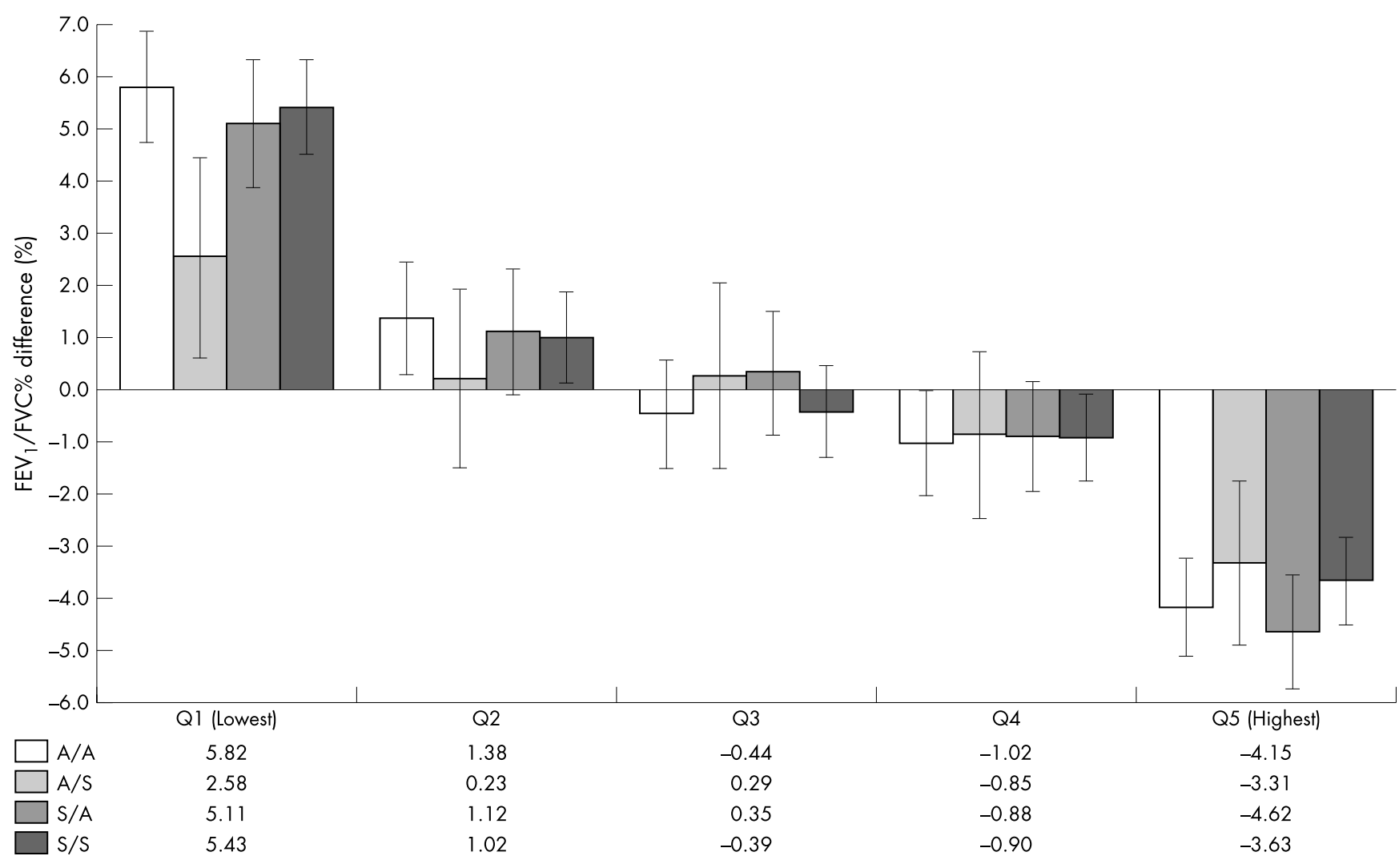

Baseline $\mathrm{FEV}_{1} / \mathrm{FVC} \%$ quintile

Figure 4 Longitudinal study for men: differences in forced expiratory volume in the first second/forced vital capacity (FEV $1 /$ FVC\%) and physical activity change categories by quintile of baseline $\mathrm{FEV}_{1} / \mathrm{FVC} \%$ (the Aerobics Center Longitudinal Study, 1971-1995).

Other studies comparing respiratory function among men engaged in various sports found that sportsmen have higher levels of function than sedentary people. Among the various groups of participants, swimmers had the maximum lung function in this cross sectional study. ${ }^{15}$ In another cross sectional study, male and female swimmers $(\mathrm{n}=459)$ had larger $\mathrm{FEV}_{1}$ values than both land based athletes and sedentary controls. ${ }^{7}$ In addition, elite male swimmers had superior $\mathrm{FEV}_{1}$ values when compared with male non-elite swimmers $(\mathrm{p}<0.05)$; however, when years of swimming training were controlled for by analysis of covariance, the difference in $\mathrm{FEV}_{1}$ between the two groups was no longer evident. This suggests that years of swimming training and/or the earlier the age at which training begins may have a significant influence on subsequent $\mathrm{FEV}_{1}$ values and swimming performance. Malkia and Impivaara ${ }^{8}$ showed in a cross sectional study that physical activity may relate to spirometric values in persons with and without bronchial asthma. Although MTT has strong associations with respiratory functions, the associations of these functions and potential risk factors were different. Because of the cross sectional nature of the study, the genetic component as a major determinant of the superior respiratory function in persons with a higher level of physical activity should be considered. ${ }^{16}$

Comprehensive pulmonary rehabilitation significantly improved exercise performance and symptoms for patients with moderate to severe chronic obstructive pulmonary disease. ${ }^{17}$ Exercise is an important component of pulmonary rehabilitation and may be associated with both physiological and psychological benefits for patients with chronic lung disease. ${ }^{18}$ Although respiratory rehabilitation programmes offer improvement in quality of life and some physiological measures, improvements in $\mathrm{FEV}_{1}$ levels have not been reported consistently. There are no reports of long term change in rates of decline in $\mathrm{FEV}_{1}$ in different exercise groups. ${ }^{19}$

In the cross sectional component of this study, those with higher physical activity levels also had higher levels of $\mathrm{FEV}_{1}$ and FVC; however, there was no difference in $\mathrm{FEV}_{1} / \mathrm{FVC} \%$. Thus, an association between physical activity and the degree of respiratory obstruction was not supported by our data.

In the longitudinal study, men in the lowest cardiorespiratory function quintile tended to have the highest variability among the four physical activity change categories (figs 1-4). This may suggest that the response of the respiratory system to physical activity is less than the response of the cardiovascular system. This may be due to the larger reserve capacity and higher lung tolerance of the cardiovascular system to the effects of physical activity, or the cardiovascular system may have more room for improvement than the respiratory system.

Although the values of $\mathrm{FEV}_{1}$ and FVC were lower in women than in men, the $\mathrm{FEV}_{1} / \mathrm{FVC} \%$ was higher in women. This suggests that lung efficiency was higher in women, or that men had more reserve capacity. This may explain why the respiratory function changes seen for men in the longitudinal study were not seen in women.

In a seven year longitudinal study of 1393 middle aged Norwegian men, ${ }^{20}$ the authors concluded that decline in physical fitness and lung function among healthy middle aged men was considerably greater among smokers than non-smokers and could not be explained by differences in age and physical activity. Smoking is the most important modifiable risk factor for decreased respiratory function. ${ }^{5}$ 19-22 We found that cigarette smoking reduced $\mathrm{FEV}_{1}, \mathrm{FVC}$, and $\mathrm{FEV}_{1} / \mathrm{FVC} \%$ in both sexes.

Although mortality from all causes is considerably increased in alcoholics, at an intake of 22-32 and 33-54 g 
alcohol a day, the relative risk of all cause death was 0.70 (95\% CI 0.59 to 0.82 ) and 0.76 (95\% CI 0.66 to 0.87 ) respectively. ${ }^{23}$ This is especially true for cardiovascular disease, and the lower risk associated with moderate alcohol intake was similar for smokers, ex-smokers, and nonsmokers. ${ }^{24}$ An alcohol consumption of $\geqslant 350 \mathrm{~g}$ a week significantly accelerated the loss of $\mathrm{FEV}_{1}$ and the loss of FVC with five years observation time controlling for smoking. ${ }^{25}$ In a 10 year study, ${ }^{26}$ cross sectional studies showed that increased alcohol consumption was significantly associated with impaired age adjusted and height adjusted $\mathrm{FEV}_{1}$ in 328 policemen, but in the longitudinal analyses, there was no relation between alcohol consumption and $\mathrm{FEV}_{1}$ decline. Twisk et al found a positive relation with alcohol consumption and FVC and $\mathrm{FEV}_{1}$ in a young population (ages 13-27 years). Sparrow et $a^{27}$ showed no relations between alcohol consumption and FVC and $\mathrm{FEV}_{1}$ in both a cross sectional and a longitudinal study after controlling for age, height, cigarette smoking habits, and educational attainment. In our study, alcohol consumption was associated with better cardiorespiratory function in only the cross sectional analyses. We did not have enough evidence to determine that alcohol consumption is related to cardiorespiratory function in our longitudinal analyses.

An overall obesity index such as BMI is not always significantly related to lung volume. ${ }^{28}$ In our study, BMI was not associated with respiratory function, whereas a higher BMI was associated with lower MTT. Being taller is associated with higher $\mathrm{FEV}_{1}$ and FVC, but with lower $\mathrm{FEV}_{1}$ / FVC\%. This suggests that tall subjects have larger lung volumes and more obstructive (or abrasive) force when air passes through the longer airway.

Age is an unmodifiable risk factor for decreased cardiorespiratory function. During childhood and adolescence there is a natural rise in lung function, after which it declines annually. Our cross sectional study suggests that, after 25 years of age, the average annual decline of $\mathrm{FEV}_{1}$ will be about $26 \mathrm{ml} /$ year for men and $22 \mathrm{ml} /$ year for women. These results are close to the estimates of the European Community for Coal and Steel equation (29 ml/year for men and $25 \mathrm{ml} /$ year for women). ${ }^{29}$

Some limitations of our study should be underscored. Firstly, this was not a controlled clinical trial. Most of our healthy adult participants were from mid to upper socioeconomic strata, so generalising to other groups (especially to clinical populations such as patients with respiratory disease) is not advised. Assessment of physical activity is difficult. Only leisure time physical activity was considered in this study. Although miles of walking and jogging as an index of physical activity had positive validation and had been used in several studies, ${ }^{140}$ we did not consider the intensity of walking and jogging and did not have any reliability studies on these data. In the longitudinal study, we lacked intermediate measures of independent variables; thus we cannot assess the influence of concurrent changes on results. Another limitation is the reliance on self reported data for physical activity and smoking, which could be influenced by poor recall, although our subjects were highly educated and aware of their health. The "regression to the mean" effects should be considered when comparing cardiorespiratory functions between two visits. In this study, baseline values of cardiorespiratory functions, as continuous or categorical variables, were controlled among compared groups. The "regression to the mean" effects will tend to dilute the effect of physical activity on cardiorespiratory functions in analyses. It cannot explain those statistical associations in this study.

In summary, our analyses suggest that physical activity and non-smoking or smoking cessation are associated

\section{Take home message}

Physical activity is important in maintaining cardiovascular and respiratory function. Change in physical activity is associated with change in cardiorespiratory fitness.

with maintaining cardiovascular and respiratory function. Change in physical activity habit is associated with cardiorespiratory fitness change, but respiratory function change contributed little to this association in adults during a five year follow up.

\section{Authors' affiliations}

Y J Cheng, The Cooper Institute, Atlanta, GA, USA

F S Sy, Centers for Disease Control and Prevention, Atlanta, GA, USA

C A Macera, San Diego State University, San Diego, CA, USA

C L Addy, University of South Carolina, Columbia, SC, USA

D Wieland, Richland Memorial Hospital, Columbia, SC, USA

S N Blair, The Cooper Institute, Dallas, TX, USA

\section{REFERENCES}

Blair SN, Kampert JB, Kohl HW III, et al. Influences of cardiorespiratory fitness and other precursors on cardiovascular disease and all-cause mortality in men and women. JAMA 1996;276:205-10.

2 Schunemann HJ, Dorn J, Grant BJ, et al. Pulmonary function is a long-term predictor of mortality in the general population: 29-year follow-up of the Buffalo Health Study. Chest 2000;1 18:656-64.

3 U.S. Department of Health and Human Services. Physical activity and health: a report of the Surgeon General. Atlanta, GA: Department of Health and Human Services, Centers for Disease Control and Prevention, National Center for Chronic Disease Prevention and Health Promotion, 1996.

4 Dunn AL, Marcus BH, Kampert JB, et al. Comparison of lifestyle and structured interventions to increase physical activity and cardiorespiratory fitness: a randomized trial. JAMA 1999:281:327-34.

5 Twisk JW, Staal BJ, Brinkman MN, et al. Tracking of lung function parameters and the longitudinal relationship with lifestyle. Eur Respir J 1998;12:627-34.

6 Burchfiel CM, Enright PL, Sharp DS, et al. Factors associated with variations in pulmonary function among elderly Japanese-American men. Chest 1997:112:87-97.

7 Doherty M, Dimitriou L. Comparison of lung volume in Greek swimmers, land based athletes, and sedentary controls using allometric scaling. Br J Sports Med 1997;31:337-41.

8 Malkia $\mathrm{E}$, Impivaara $\mathrm{O}$. Intensity of physical activity and respiratory function in subjects with and without bronchial asthma. Scand J Med Sci Sports 1998;8:27-32

9 Tiep BL. Disease management of COPD with pulmonary rehabilitation. Chest 1997:112:1630-56.

10 Burrows B, Cline MG, Knudson RJ, et al. A descriptive analysis of the growth and decline of the FVC and FEV1. Chest 1983;83:717-24.

11 Tager IB, Hollenberg M, Satariano WA. Association between self-reported leisure-time physical activity and measures of cardiorespiratory fitness in an elderly population. Am J Epidemiol 1998;147:921-31.

12 Balke B, Ware RW. An experimental study of physical fitness in Air Force personnel. US Armed Forces Med J 1959; 10:675-88.

13 Neas LM, Schwartz J. Pulmonary function levels as predictors of mortality in a national sample of US adults. Am J Epidemiol 1998;147:1011-18.

$14 \mathrm{Kohl} \mathrm{HW,} \mathrm{Blair} \mathrm{SN,} \mathrm{Paffenbarger} \mathrm{RS,} \mathrm{et} \mathrm{al.} \mathrm{A} \mathrm{mail} \mathrm{survey} \mathrm{of} \mathrm{physical} \mathrm{activity}$ habits as related to measured physical fitness. Am J Epidemiol 1988;127:1228-39.

15 Mehrotra PK, Varma N, Tiwari S, et al. Pulmonary functions in Indian sportsmen playing different sports. Indian J Physiol Pharmacol 1998;42:412-16.

16 Lewitter FI, Tager IB, McGue M, et al. Genetic and environmental determinants of level of pulmonary function. Am J Epidemiol 1984; 120:518-30.

17 Ries AL, Kaplan RM, Limberg TM, et al. Effects of pulmonary rehabilitation on physiologic and psychosocial outcomes in patients with chronic obstructive pulmonary disease. Ann Intern Med 1995;122:823-32.

18 Ries AL. The importance of exercise in pulmonary rehabilitation. Clin Chest Med 1994; 15:327-37.

19 Kerstiens HA, Rijcken B, Schouten JP, et al. Decline of FEV1 by age and smoking status: facts, figures, and fallacies. Thorax 1997;52:820-7.

20 Sandvik L, Erikssen G, Thaulow E. Long term effects of smoking on physical fitness and lung function: a longitudinal study of 1393 middle aged Norwegian men for seven years. BMJ 1995:311:715-18.

21 Burchfiel CM, Marcus EB, Curb JD, et al. Effects of smoking and smoking cessation on longitudinal decline in pulmonary function. Am J Respir Crit Care Med 1995; 151:1778-85.

22 Belousova EG, Haby MM, Xuan W, et al. Factors that affect normal lung function in white Australian adults. Chest 1997;112:1539-46. 
23 Taylor JR, Combs-Orme T, Taylor DA. Alcohol and mortality. Diagnostic considerations. J Stud Alcohol 1983:44:17-25.

24 Renaud SC, Gueguen R, Schenker J, et al. Alcohol and mortality in middleaged men from eastern France. Epidemiology 1998;9:184-8.

25 Lange $\mathbf{P}$, Groth S, Mortensen J, et al. Pulmonary function is influenced by heavy alcohol consumption. Am Rev Respir Dis 1988;137:11119-23.

26 Zureik M, Liard R, Kauffmann F, et al. Alcohol consumption, gamma-glutamyl transpeptidase (GGT), and pulmonary function: a cross-sectional and longitudinal study in working men. Alcohol Clin Exp Res 1996:20:1507-11.
27 Sparrow D, Rosner B, Cohen $M$, et al. Alcohol consumption and pulmonary function. A cross-sectional and longitudinal study. Am Rev Respir Dis 1983;127:735-8

28 Sue DY. Obesity and pulmonary function: more or less? Chest 1997;111:844-5.

29 Quanier PH. Standardized lung function testing. Bull Eur Physiopathol Respir 1983;19(suppl 5):1-95.

30 Cheng Y, Macera CA, Davis DR, et al. Physical activity and self-reported, physician-diagnosed osteoarthritis: is physical activity a risk factor? J Clin Epidemiol 2000;53:315-22.

\section{Want to extend your search?}

\section{Cross journal searching}

Can't find what you're looking for in British Journal of Sports Medicine? Extend your search across 340+ journals. Search restriction options include specific subject areas (eg. clinical medicine, basic research), select specific journals or search all available titles.

\section{www.bjsportmed.com}

